\title{
Dose Reduction of Tumor Necrosis Factor Inhibitor and its Effect on Medical Costs for Patients with Ankylosing Spondylitis
}

\author{
Bon San Koo · Yu-Cheol Lim · Min-Young Lee · Ja-Young Jeon • \\ Hyun-Jeong Yoo · In-Sun Oh · Ju-Young Shin • Tae-Hwan Kim (D)
}

Received: November 18, 2020 / Accepted: December 19, 2020 / Published online: January 9, 2021

(c) The Author(s) 2021

\begin{abstract}
Introduction: Tumor necrosis factor inhibitors (TNFis) may be administered at a reduced dose to patients with ankylosing spondylitis (AS) for various reasons. However, in practice, there is insufficient evidence of how the dose reduction of TNFi is implemented and the amount of medical costs it reduces. In this study, we investigated treatment patterns among patients
\end{abstract}

Bon San Koo and Yu-Cheol Lim contributed equally to this study.

Supplementary Information The online version contains supplementary material available at https:// doi.org/10.1007/s40744-020-00274-9.

B. S. Koo

Department of Internal Medicine, Inje University Seoul Paik Hospital, Inje University College of Medicine, Seoul, Republic of Korea

Y.-C. Lim · I.-S. Oh · J.-Y. Shin

School of Pharmacy, Sungkyunkwan University, Suwon, Gyeonggi-do, Republic of Korea

M.-Y. Lee

VIAplus, Suwon, Gyeonggi-do, Republic of Korea

J.-Y. Jeon · H.-J. Yoo

Pfizer Inc, Seoul, Republic of Korea

T.-H. Kim ( $₫)$

Department of Rheumatology, Hanyang University Hospital for Rheumatic Diseases, Seoul, Republic of Korea

e-mail: thkim@hanyang.ac.kr with AS who were administered various TNFis. The effect on medical costs related to AS was also investigated using Korea's insurance claims database.

Methods: From the insurance claims database of the Health Insurance Review \& Assessment Service in South Korea, patients with AS newly treated with TNFis (etanercept, adalimumab, golimumab, and infliximab) between July 1, 2013, and June 30, 2016, were enrolled. Patients treated with the TNFis were followed up for 2 years. Treatment patterns (continuation and discontinuation of TNFi) and dose reduction $(<50 \%$ of recommended dose) in patients who continued treatment were analyzed and compared among the TNFi groups using the Chisquare test. Healthcare costs between the dose reduction and maintenance groups were compared using general linear modeling.

Results: Of 1352 patients, 764 (56.51\%) continued using TNFis for 2 years, and $17.8 \%$ of these were administered reduced doses. TNFi dose reduction was the most frequent in 36 (24.83\%) patients using etanercept, followed by those using adalimumab (21.97\%), golimumab $(11.70 \%)$, and infliximab (11.98\%) $(p=0.0028)$. For each TNFi group, the total healthcare cost significantly decreased, that is, by $24.85 \%$ for adalimumab, $31.80 \%$ for etanercept, $26.34 \%$ for golimumab, and $35.52 \%$ for infliximab $(p<0.0001)$.

Conclusions: TNFi dose reduction was identified in $17.8 \%$ of the patients with AS, and the 
patterns were different for each TNFi. Additionally, the dose reductions significantly reduced the medical costs associated with AS, that is, from 24.85 to $35.52 \%$ of the total medical expenditure.

Keywords: Ankylosing spondylitis; Biological product; Epidemiology; Healthcare cost; Tumor necrosis factor inhibitor

\section{Key Summary Points}

\section{Why carry out this study?}

During the treatment of patients with ankylosing spondylitis, tumor necrosis factor inhibitor dosage is often reduced for various reasons.

We analyzed the pattern of tumor necrosis factor inhibitor treatment and the impact of dose reduction on medical costs of patients with ankylosing spondylitis using national insurance data.

\section{What was learned from the study?}

Overall, $17.8 \%$ of patients received less than $50 \%$ of their initial tumor necrosis factor inhibitor dose within 2 years.

The pattern of dose reduction was different for each TNFi.

The cost of AS-related total medical care significantly decreased, i.e., from 24.85 to $35.52 \%$ of the total medical expenditure, following TNFi dose reduction.

\section{DIGITAL FEATURES}

This article is published with digital features, including a summary slide, to facilitate understanding of the article. To view digital features for this article go to https://doi.org/10.6084/ m9.figshare.13397357.

\section{INTRODUCTION}

Various biologics have been developed and used in clinical practice for the treatment of rheumatic diseases $[1,2]$. Among biologics, tumor necrosis factor inhibitors (TNFis) have shown good efficacy in patients with ankylosing spondylitis (AS) who were unresponsive to nonsteroidal anti-inflammatory drugs [3-7]. They reduce disease activity in and improve the quality of life of patients with AS [5, 6]. However, long-term treatment with TNFis increases the incidence of adverse effects, such as infections, and the economic burden on both patients with AS and the nation $[8,9]$.

When a low disease activity is maintained by TNFis, the discontinuation or tapering of TNFis is considered for various reasons. However, it is difficult to predict the worsening of disease activity with the discontinuation or tapering. In studies that examined the discontinuation of biologics for AS, more than $70 \%$ of patients who discontinued TNFis experienced spondylitis flares within 1 year $[10,11]$. As the discontinuation of TNFis is associated with the risk of flare, reducing the dose is considered better than discontinuing the biologics to maintain a low disease activity [9]. Although TNFi tapering may be advantageous to maintain a low disease activity than discontinuation, there is limited evidence on the effects of tapering, and it should be carried out with caution [12]. Thus, more real-world evidence of TNFi therapy is needed to establish effective treatments for AS.

In this study, using Korea's nationwide health insurance service claims data, the treatment patterns among patients with AS administered TNFis were analyzed. Additionally, the changes in medical costs according to TNFi dose reduction were investigated.

\section{METHODS}

\section{Data Source}

In this study, we used research data created by the Health Insurance Review \& Assessment Service (HIRA) of the Republic of Korea (M20180306928). The views expressed are those 
of the authors and do not necessarily reflect those of the HIRA and the Ministry of Health and Welfare. The HIRA database consists of administrative claims data submitted by healthcare service providers to the HIRA for reimbursement for a service provided to patients. As almost all South Korean citizens (approximately 50 million) are covered by this insurance system, it could be representative of the South Korean population [13-15].

The database contains not only demographic information and healthcare utilization information, including surgical, medical, pharmaceutical services, and clinical diagnostic codes [International Classification of Disease, 10th Revision (ICD-10)] of each patient but also the medical costs of each service availed $[13,16]$. Thus, this database is useful for estimating the treatment patterns and changes in healthcare costs. In a previous validation study, which compared diagnoses derived from the database of medical records of patients, the overall positive predictive value of the diagnostic codes was approximately $76.5-83.6 \%$ [17].

\section{Study Design}

In this study, we investigated the treatment patterns among patients with AS administered various TNFis. We defined the index date for each study subject as the date of the first occurrence of claim for the administration of any TNFi of interest between July 1, 2013, and June 30,2015 , which was considered the identification period. The index TNFi was defined as the TNFi prescribed on the index date. We defined a 2-year period after the index date as the follow-up period, and a 1-year period before the index date as the pre-index period. The baseline characteristics of the study population were assessed in the pre-index period; concomitant medication was assessed in the followup period (Fig. 1).

\section{Study Population}

This study involved patients who (1) had at least one insurance claim with both an AS diagnosis code (ICD-10: M45) as a primary or secondary diagnosis code (up to 5) and the codes for Rare and Intractable Diseases registration (RID) program for AS (V140) during the identification period; (2) were prescribed the TNFi of interest (etanercept, adalimumab, golimumab, or infliximab) within the same claim; and (3) were aged $\geq 18$ years at the index date. Patients could be assessed using the RID program only if they met the modified New York criteria, which is a system that offers special cost-benefit to patients with a chronic illness. Thus, both codes (M45 and V140) can ensure that the included patients had AS [18]. To ensure the inclusion of TNFi-naive patients, patients prescribed any biologics (adalimumab, etanercept, golimumab, and infliximab, including infliximab biosimilars) within the pre-index period were excluded. By excluding these patients, we could avoid the influence of the use of previous biologics. Similarly, the patients who had at least one insurance claim including a diagnosis code for other indications of the index TNFi (rheumatoid arthritis: M05, M06; psoriatic arthritis: M07.0, M07.1, M07.2, M07.3, M09.0, L40.5; Crohn's disease: K50; psoriasis: L40; ulcerative colitis: K51; Behçet's disease: M35.2, N77.8; hidradenitis suppurativa: L73.2) during the preceding year were excluded from the study. Patients who could not be followed up for 2 years were excluded from this study. For infliximab, the follow-up period started from the fourth infusion of infliximab, because an induction period during the first 6 weeks (weeks 0,2 , and 6) is required for the administration of infliximab [19]. Patients were classified into each TNFi group according to their index TNFi.

This study was performed in accordance with the Helsinki Declaration of 1964 and its later amendments. The study protocol was approved by the institutional review boards of the Inje University Seoul Paik Hospital (2018-07-011), Sungkyunkwan University (SKKU 2018-02-006), and Hanyang University (2017-11-020). Informed consent was waived by the institutional review boards because this was a retrospective study that used data from insurance claims. 


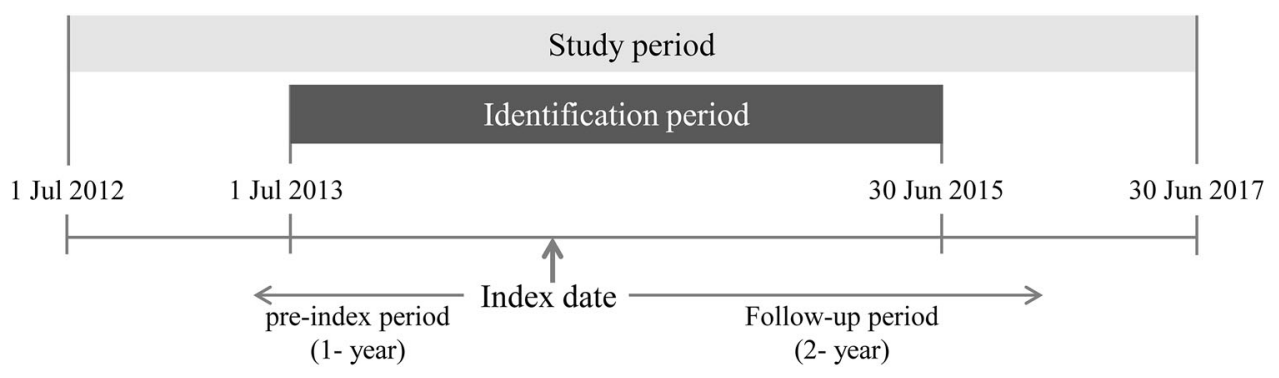

Fig. 1 Flow diagram. The diagram described the process of study population selection from the Health Insurance Review and Assessment claims database

\section{Study Outcomes}

The primary outcomes were the treatment patterns of TNFis during the follow-up periods in each treatment group. The treatment patterns were classified into two large groups: continuation and discontinuation. Discontinuation was further subdivided into three categories: switching, restarting, and stopping. Switching was defined as a change from index TNFi to another TNFi within 90 days from the last exposure period of the index TNFi. The TNFi exposure period was assumed to be 7 days for each administration of $50 \mathrm{mg}$ etanercept, 14 days for each administration of $40 \mathrm{mg}$ adalimumab, 28 days for each administration of $50 \mathrm{mg}$ golimumab, and 56 days for each administration of infliximab [20]. Restarting was defined as prescribing index TNFi or other TNFi after more than 90 days from the last exposure period. Stopping was defined as no prescription of the index TNFi after the last exposure period without switching or restarting. Patients who had been continuously prescribed the index TNFi without any defined discontinuation event during the 2-year followup period were assigned to the continuation group.

A dose reduction of TNFi was evaluated in patients listed in the continuation group in each TNFi group. To estimate dose reduction, the weekly dose was calculated as the prescribed dosage divided by the time gap between consecutive prescriptions. The patients who were prescribed a weekly dose of $50 \%$ or lower of the recommended weekly dose of the index TNFi in a series of $\geq 2$ claims during the follow-up period were classified into the dose reduction group, whereas the others were classified into the maintenance group [20]. We referred to the drug approval documents of the Ministry of Food and Drug Safety to define the recommended weekly doses (adalimumab: $40 \mathrm{mg}$ every 14 days; etanercept: $50 \mathrm{mg}$ every 7 days; golimumab: $50 \mathrm{mg}$ every 28 days; infliximab: $5 \mathrm{mg} / \mathrm{kg}$ every 56 days). The recommended weekly dose of infliximab was estimated from the average weight for men $(71 \mathrm{~kg})$ and women $(57 \mathrm{~kg})$ in South Korea [21]. The amount of reduced dose was calculated from the amount of reduction in the weekly dose, which was obtained by subtracting the first reduced weekly dose from the recommended weekly dose. The reduced percentage was estimated as the amount of reduced dose divided by the recommended weekly dose. Time to dose reduction was calculated as the number of days from the index date to the date of dose reduction (Table 1). A sensitivity analysis was performed by changing the definition of dose reduction to the following: a weekly dose of $30 \%$ or lower of the recommended weekly dose of the index TNFi in a series of $\geq 2$ claims during the followup period.

To compare AS-related healthcare costs between the dose reduction and dose maintenance groups for each index TNFi, we estimated the costs from the patients' claims that had an AS diagnosis code (M45) and a specialized diagnosis code (V140) during the follow-up period. The AS-related healthcare cost was subdivided into TNFi costs, other drug costs, and other medical costs. Other drug costs represented the costs of drugs except for TNFis, and 
other medical costs represented the AS-related healthcare costs, except for the costs of the drugs. All costs are expressed in U.S. dollars at the May 2019 exchange rate $(1206$ won = 1 US dollar).

\section{Statistical Analysis}

The patient baseline characteristics and treatment patterns are presented as number and percentage of patients in each TNFi group. Chisquare test or Fisher's exact test was used to test for significant differences between groups.

In the dose reduction analysis via index TNFi, dose reduction occurrences are presented as the number and percentage of patients. The amount of dose reduction $(\mathrm{mg})$ and time to dose reduction (days) are presented as mean (standard deviation) and median (interquartile range). For the results presented as mean and standard deviation, analysis of variance was used to compare the differences among the TNFi groups. Kruskal-Wallis test was used to compare the differences presented as median and interquartile range.

Healthcare costs are presented as regressionadjusted predicted least-square mean cost from the generalized linear model (GLM) with gamma distribution and log link function. The GLM was used to estimate healthcare costs because healthcare cost data usually have a skewed distribution [22]. Demographic covariates including sex, age, and Charlson comorbidity index were adjusted by the model.

All statistical tests were two-sided with an alpha level of 0.05 . The data were analyzed using SAS software (version 9.4, SAS Institute, Cary, NC, USA).

Table 1 Definition of terms

\begin{tabular}{|c|c|}
\hline Term & Definition \\
\hline Last exposure period & $\begin{array}{l}\text { Defined as a period from the date when each patient's last TNFi prescribed to the expected end date } \\
\text { of supply of the last prescribed TNFi }\end{array}$ \\
\hline Continuation & $\begin{array}{l}\text { Defined as a case that was continuously treated with the index TNFi without any discontinuation } \\
\text { event during the follow-up period }\end{array}$ \\
\hline Discontinuation & Defined as a case that had any discontinuation event (switch, restart, or stopping) \\
\hline Switch & $\begin{array}{l}\text { Defined as a case that changed from the index TNFi to the other TNFi within } 90 \text { days treatment } \\
\text { gap, followed by the last exposure period }\end{array}$ \\
\hline Restart & $\begin{array}{l}\text { Defined as a case that restarts the index TNFi or the other TNFi with treatment gap }>90 \text { days, } \\
\text { followed by the last exposure period }\end{array}$ \\
\hline Stopping & Defined as a case that had no prescription for the index TNFi after the last exposure period \\
\hline Dose reduction & Defined as a case with a series of prescriptions $(\geq 2)$ with reduced dose \\
\hline Case of reduction & $\begin{array}{l}\text { The prescribed dosage in one prescription } \\
\text { The time gap between two consecutive prescriptions } \\
\times 7 \text { days } / \text { week }<0.5 \times \text { The recommended weekly dose }\end{array}$ \\
\hline $\begin{array}{l}\text { Amount of reduced } \\
\text { dose }\end{array}$ & The recommended weekly dose - The first reduced weekly dose \\
\hline Reduced percentage & $\frac{\text { The recommended weekly dose-The first reduced weekly dose }}{\text { The recommended weekly dose }} \times 100$ \\
\hline
\end{tabular}

TNFi tumor necrosis factor inhibitor 


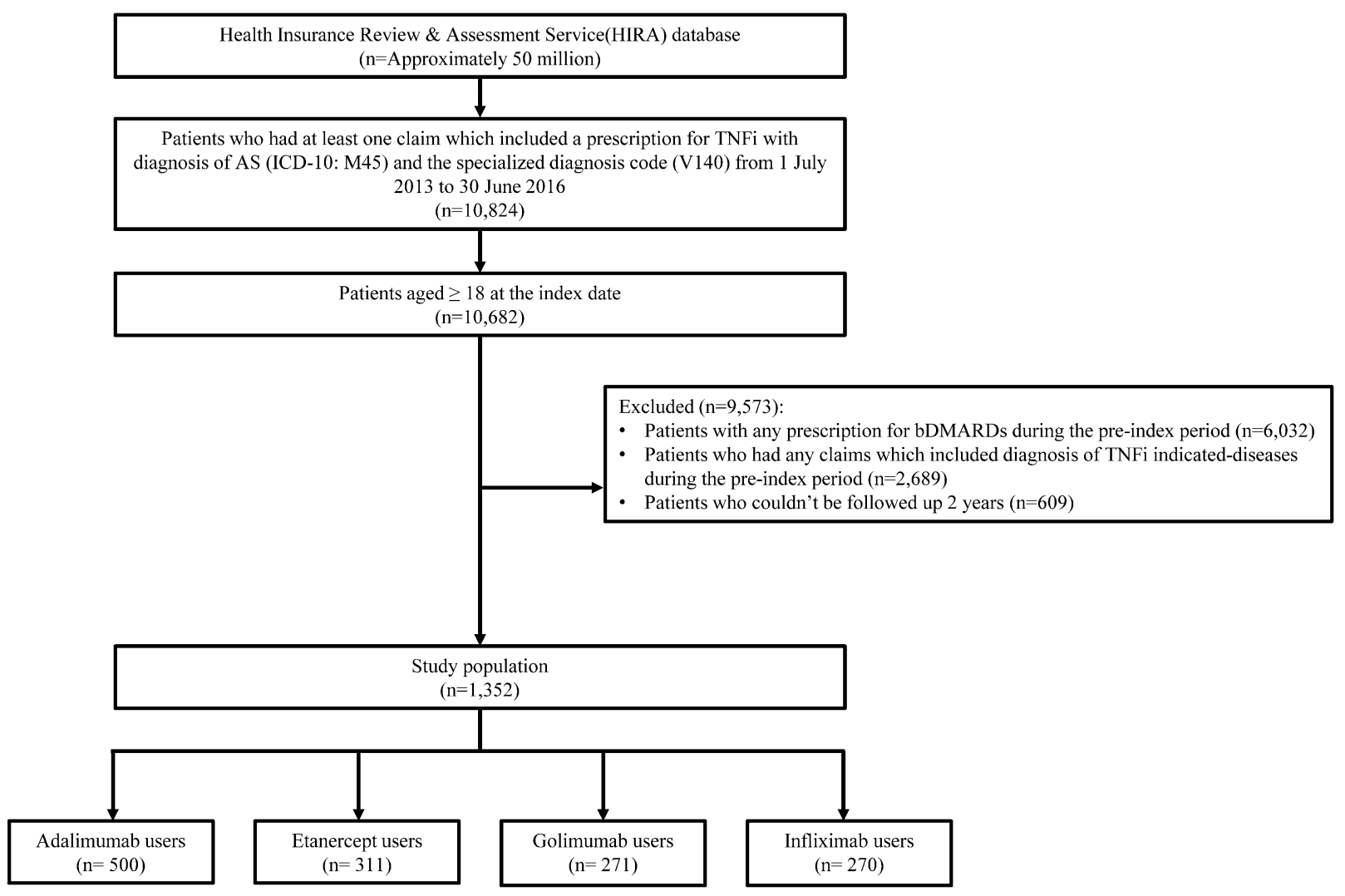

Fig. 2 Study design. The index date was defined as the date of the first occurrence of the claim with one of the TNFis during the identification period. The pre-index period was defined as a period of 1 year before the index date to select the study population and measure their baseline characteristics. The entire study population was followed up for 2 years

\section{RESULTS}

\section{Clinical Characteristics of Patients}

A total of 10,824 patients with AS were treated with a TNFi at least once per the claims data (Fig. 2). Of these, 1352 patients were enrolled in this study. Among these patients, 500 patients were treated with adalimumab, 311 with etanercept, 271 with golimumab, and 270 with infliximab (Table 2).

\section{Difference in Treatment Patterns Between TNFis}

Table 3 shows the treatment patterns in the TNFi groups during the 2-year follow-up period. Of the 1352 patients, 764 (56.51\%) continued TNFi treatment. In the discontinuation group, the TNFi that was most and less frequently discontinued was etanercept $(53.38 \%)$ and golimumab (30.64\%), respectively. The switching group, restarting group, and stopping group represented $6.73,16.72$, and $20.04 \%$ of the total study subjects, respectively. The rate of switching to another TNFi from infliximab was higher $(10.74 \%)$ than that from the other TNFis. High rates of switching were observed from infliximab to golimumab (5.56\%) and adalimumab $(3.33 \%)$, from adalimumab to etanercept (3\%), and from etanercept to adalimumab (4.82\%). The rate of restarting was not significantly different among the TNFis; however, the rate of stopping was significantly different $(23.00 \%$ in adalimumab, $24.76 \%$ in etanercept, $14.81 \%$ in golimumab, and $14.81 \%$ in infliximab; $p<0.0001)$. 
Table 2 Clinical baseline characteristics of study population with initiating TNFi for AS

\begin{tabular}{|c|c|c|c|c|c|c|}
\hline Characteristics & $\begin{array}{l}\text { ADL } \\
500\end{array}$ & $\begin{array}{l}\text { ETN } \\
311\end{array}$ & $\begin{array}{l}\text { GLM } \\
271\end{array}$ & $\begin{array}{l}\text { IFX } \\
270\end{array}$ & $\begin{array}{l}\text { Total } \\
1352\end{array}$ & $p$ value* \\
\hline \multicolumn{6}{|l|}{ Age (years) } & \multirow[t]{6}{*}{0.0541} \\
\hline $18-29, n(\%)$ & $147(29.40)$ & $71(22.83)$ & $76(28.04)$ & $84(31.11)$ & $78(27.96)$ & \\
\hline $30-39, n(\%)$ & $161(32.20)$ & $81(26.05)$ & $90(33.21)$ & $79(29.26)$ & $411(30.40)$ & \\
\hline $40-49, n(\%)$ & $106(21.20)$ & $80(25.72)$ & $63(23.25)$ & $55(20.37)$ & $304(22.49)$ & \\
\hline $50-64, n(\%)$ & $72(14.40)$ & $71(22.83)$ & $36(13.28)$ & $45(16.67)$ & $224(16.57)$ & \\
\hline$\geq 65, n(\%)$ & $14(2.80)$ & $8(2.57)$ & $6(2.21)$ & $7(2.59)$ & $35(2.59)$ & \\
\hline Female, $n(\%)$ & $94(18.58)$ & $51(16.29)$ & $53(20.15)$ & $51(18.89)$ & $249(18.42)$ & 0.7611 \\
\hline \multicolumn{6}{|c|}{ Charlson comorbidity index (CCI) score } & \multirow[t]{5}{*}{0.7660} \\
\hline $0, n(\%)$ & $234(46.80)$ & $152(48.87)$ & $133(49.08)$ & $131(48.52)$ & $650(48.08)$ & \\
\hline $1, n(\%)$ & $165(33.00)$ & $88(28.30)$ & $79(29.15)$ & $87(32.22)$ & $419(30.99)$ & \\
\hline $2, n(\%)$ & $59(11.80)$ & $34(10.93)$ & $35(12.92)$ & $28(10.37)$ & $156(11.54)$ & \\
\hline$\geq 3, n(\%)$ & $42(8.40)$ & $37(11.90)$ & $24(8.86)$ & $24(8.89)$ & $127(9.39)$ & \\
\hline \multicolumn{7}{|c|}{ Prior medication, $n(\%)$} \\
\hline Methotrexate & $70(14.00)$ & $37(11.90)$ & $41(15.13)$ & $31(11.48)$ & $179(13.24)$ & 0.5109 \\
\hline Sulfasalazine & $315(63.00)$ & $152(48.87)$ & $161(59.41)$ & $181(67.04)$ & $809(59.84)$ & $<0.0001$ \\
\hline Corticosteroid & $338(67.60)$ & $200(64.31)$ & $193(71.22)$ & $196(72.59)$ & $927(68.57)$ & 0.1246 \\
\hline \multicolumn{7}{|c|}{ Concomitant medication, $n(\%)$} \\
\hline Methotrexate & $58(11.60)$ & $41(13.18)$ & $35(12.92)$ & $30(11.11)$ & $164(12.13)$ & 0.8314 \\
\hline Sulfasalazine & $135(27.00)$ & $70(22.51)$ & $73(26.94)$ & $94(34.81)$ & $372(27.51)$ & 0.0105 \\
\hline Corticosteroid & $305(61.00)$ & $202(64.95)$ & $164(60.52)$ & $213(78.89)$ & $884(65.38)$ & $<0.0001$ \\
\hline
\end{tabular}

$T N F i$ tumor necrosis factor inhibitor, $A S$ ankylosing spondylitis, $A D L$ adalimumab, ETN etanercept, GLM golimumab, IFX infliximab

${ }^{*}$ Chi-square test

\section{Dose Reduction in Patients Continuously Treated With TNFis}

Among the 764 patients who continued TNFi treatment, 136 patients $(17.80 \%)$ were treated with a reduced dose within 2 years (Table 4 ). The percentage of patients with dose reduction was as follows: $21.97 \%$ with adalimumab, $24.83 \%$ with etanercept, $11.70 \%$ with golimumab, and $11.98 \%$ with infliximab $(p=0.0028)$. In these patients, the mean reduced percentage of the dose of adalimumab, etanercept, golimumab, and infliximab was $58.10,60.45,57.32$, and $58.35 \%$, respectively, of the recommended weekly doses; these were not significantly different among the TNFi groups $(p=0.8673)$. The mean time to dose reduction was significantly different among the TNFi groups $(p=0.0294)$. The dose of etanercept was decreased first $(297.44 \pm 219.11$ days $)$, followed by adalimumab (365.02 \pm 192.36 days), infliximab (380.60 \pm 121.78 days), and golimumab (448.59 \pm 157.14 days). In the sensitivity analysis, 234 patients (30.63\%) were 
Table 3 Treatment patterns of patients with initiating TNFi for AS

\begin{tabular}{|c|c|c|c|c|c|c|}
\hline Treatment patterns & $\begin{array}{l}\text { ADL } \\
500\end{array}$ & $\begin{array}{l}\text { ETN } \\
311\end{array}$ & $\begin{array}{l}\text { GLM } \\
271\end{array}$ & $\begin{array}{l}\text { IFX } \\
270\end{array}$ & $\begin{array}{l}\text { Total } \\
1352\end{array}$ & $p$ value \\
\hline Continuation & $264(52.80)$ & $145(46.62)$ & $188(69.37)$ & $167(61.85)$ & $764(56.51)$ & $<0.0001^{*}$ \\
\hline Discontinuation & $236(47.20)$ & $166(53.38)$ & $83(30.64)$ & $103(38.14)$ & $588(43.49)$ & $<0.0001^{*}$ \\
\hline Switching & $32(6.40)$ & $20(6.43)$ & $10(3.70)$ & $29(10.74)$ & $91(6.73)$ & $<0.0001^{* *}$ \\
\hline to $\mathrm{ADL}$ & $0(0.00)$ & $15(4.82)$ & $4(1.48)$ & $9(3.33)$ & $30(2.22)$ & \\
\hline to ETN & $15(3.00)$ & $0(0.00)$ & $3(1.11)$ & $5(1.85)$ & $24(1.78)$ & \\
\hline to GLM & $10(2.00)$ & $4(1.29)$ & $0(0.00)$ & $15(5.56)$ & $26(1.92)$ & \\
\hline to IFX & $7(1.40)$ & $1(0.32)$ & $3(1.11)$ & $0(0.00)$ & $11(0.81)$ & \\
\hline Restarting & $89(17.80)$ & $69(22.19)$ & $34(12.55)$ & $34(12.59)$ & $226(16.72)$ & $0.0596^{*}$ \\
\hline to other & $7(1.40)$ & $7(2.25)$ & $0(0.00)$ & $6(2.22)$ & $20(1.48)$ & \\
\hline \multicolumn{7}{|l|}{ TNFi } \\
\hline to same & $82(16.40)$ & $62(19.94)$ & $34(12.55)$ & $28(10.37)$ & $206(15.24)$ & \\
\hline \multicolumn{7}{|l|}{ TNFi } \\
\hline Stopping & $115(23.00)$ & $77(24.76)$ & $39(14.39)$ & $40(14.81)$ & $271(20.04)$ & $<0.0001^{*}$ \\
\hline
\end{tabular}

$T N F i$ tumor necrosis factor inhibitor, $A S$ ankylosing spondylitis, $A D L$ adalimumab, ETN etanercept, GLM golimumab, IFX infliximab

${ }^{*}$ Chi-square test

**Fisher's exact test

treated with 30\% reduced dose during the follow-up period, with adalimumab being the most common agent (39.02\%), followed by etanercept (34.48\%), golimumab $(30.32 \%)$, and infliximab $(14.37 \%, \mathrm{p}=0.0001)$ (See Table S1 for details).

\section{Healthcare Cost Changes Associated with Dose Reduction}

Figure 3 shows the AS-related healthcare costs in the TNFi groups. When the reduced dose was administered, the cost of TNFi decreased by $26.20,32.22,24.23$, and $36.87 \%$ for adalimumab, etanercept, golimumab, and infliximab, respectively, and the total cost decreased by $24.85,31.80,26.34$, and $35.52 \%$, respectively $(p<0.0001$ in all comparisons). Among the TNFi groups, other drug costs and other medical costs were unaltered; however, the dose reduction group of golimumab showed significantly lower other drug $(p=0.0013)$ and other medical $(p=0.0019)$ costs than the dose maintenance group.

\section{DISCUSSION}

The results of this study show that each TNFi has a different treatment pattern and that TNFis can be prescribed with frequent dose reduction within 2 years. Of those who continued to receive TNFis, $17.80 \%$ had a reduction in dosage within 2 years. In addition, dose reduction was found to result in a significant increase in medical cost savings and a reduction in the cost of providing TNFis.

We identified significantly different prescription patterns among TNFis. High frequencies of golimumab and infliximab continuation and adalimumab and etanercept stopping were observed. With regard to switching, most TNFis were switched to the subcutaneous injection, 
Table 4 Analysis of dose reduction TNFi in patients who were continuously treated with TNFi

\begin{tabular}{|c|c|c|c|c|c|}
\hline & \multicolumn{5}{|c|}{ 2-year of follow-up $(n=764)$} \\
\hline & $\begin{array}{l}\text { ADL } \\
264\end{array}$ & $\begin{array}{l}\text { ETN } \\
145\end{array}$ & $\begin{array}{l}\text { GLM } \\
188\end{array}$ & $\begin{array}{l}\text { IFX } \\
167\end{array}$ & $p$ value \\
\hline $\begin{array}{l}\text { Recommended weekly dose } \\
\quad(\mathrm{mg})^{\mathrm{a}}\end{array}$ & 20 & 50 & 12.5 & $44.38^{b}$ & \\
\hline \multicolumn{6}{|l|}{ Dose reduction } \\
\hline Percentage of patients, $n(\%)$ & $58(21.97)$ & $36(24.83)$ & $22(11.70)$ & $20(11.98)$ & $0.0028^{*}$ \\
\hline \multicolumn{6}{|l|}{ Index weekly dose (mg) } \\
\hline Mean (SD) & $17.31(5.25)$ & $37.92(13.52)$ & $11.22(1.88)$ & $25.69(9.75)$ & \\
\hline Median (IQR) & $\begin{array}{l}18.67 \\
\quad(15.56-19.31)\end{array}$ & $\begin{array}{l}43.75 \\
\quad(24.56-48.28)\end{array}$ & $\begin{array}{l}11.67 \\
\quad(10.94-12.07)\end{array}$ & $\begin{array}{l}24.15 \\
\quad(21.54-29.87)\end{array}$ & \\
\hline \multicolumn{6}{|l|}{$\begin{array}{l}\text { Amount of reduced dose } \\
(\mathrm{mg})\end{array}$} \\
\hline Mean (SD) & $11.62(1.89)$ & $30.23(5.94)$ & $7.16(0.96)$ & $25.64(3.72)$ & \\
\hline Reduced percentage (\%) & 58.10 & 60.45 & 57.32 & 58.35 & $0.8673^{*}$ \\
\hline Median (IQR) & $\begin{array}{l}10.87 \\
\quad(10.18-14.72)\end{array}$ & $\begin{array}{l}27.95 \\
\quad(25.44-32.79)\end{array}$ & $7.16(6.36-7.57)$ & $\begin{array}{l}24.61 \\
\quad(22.50-27.74)\end{array}$ & \\
\hline \multicolumn{6}{|l|}{$\begin{array}{l}\text { Time to dose reduction } \\
\text { (days) }\end{array}$} \\
\hline Mean (SD) & $365.02(192.36)$ & $297.44(219.11)$ & $448.59(157.14)$ & $380.6(121.78)$ & $0.0294^{* *}$ \\
\hline Median (IQR) & $377(169-518)$ & $\begin{array}{l}193 \\
\quad(121.5-482.5)\end{array}$ & $443(332-596)$ & $387.5(256-503)$ & $0.0224^{* * *}$ \\
\hline
\end{tabular}

$T N F i$ tumor necrosis factor inhibitor, $A D L$ adalimumab, $E T N$ etanercept, $G L M$ golimumab, $I F X$ infliximab, $S D$ standard deviation, $I Q R$ interquartile range

${ }^{*}$ Chi-square test

${ }^{* *}$ ANOVA test

${ }^{* * *}$ Kruskal-Wallis test

${ }^{a}$ Referred from Ministry of Food and Drug Safety drug approval documents

b Reflected average weights for Korean

such as adalimumab, etanercept, and golimumab. In addition, the frequencies of restarting and stopping were high for adalimumab and etanercept. We suggest that adalimumab and etanercept might have the advantage of being administered depending on symptoms because of their lower price and shorter intervals per injection than golimumab and infliximab; additionally, these TNFis could be administered through self-injection that allows the patient to decide when to inject. Thus, dose reduction appears to be more frequent and earlier for adalimumab and etanercept than for the other TNFis; this may also be owing to the different methods of administration rather than the treatment effect alone.

To compare the treatment patterns among TNFis, dosing was standardized. In a manner similar to that in previous studies [23, 24], our data are presented with the recommended 

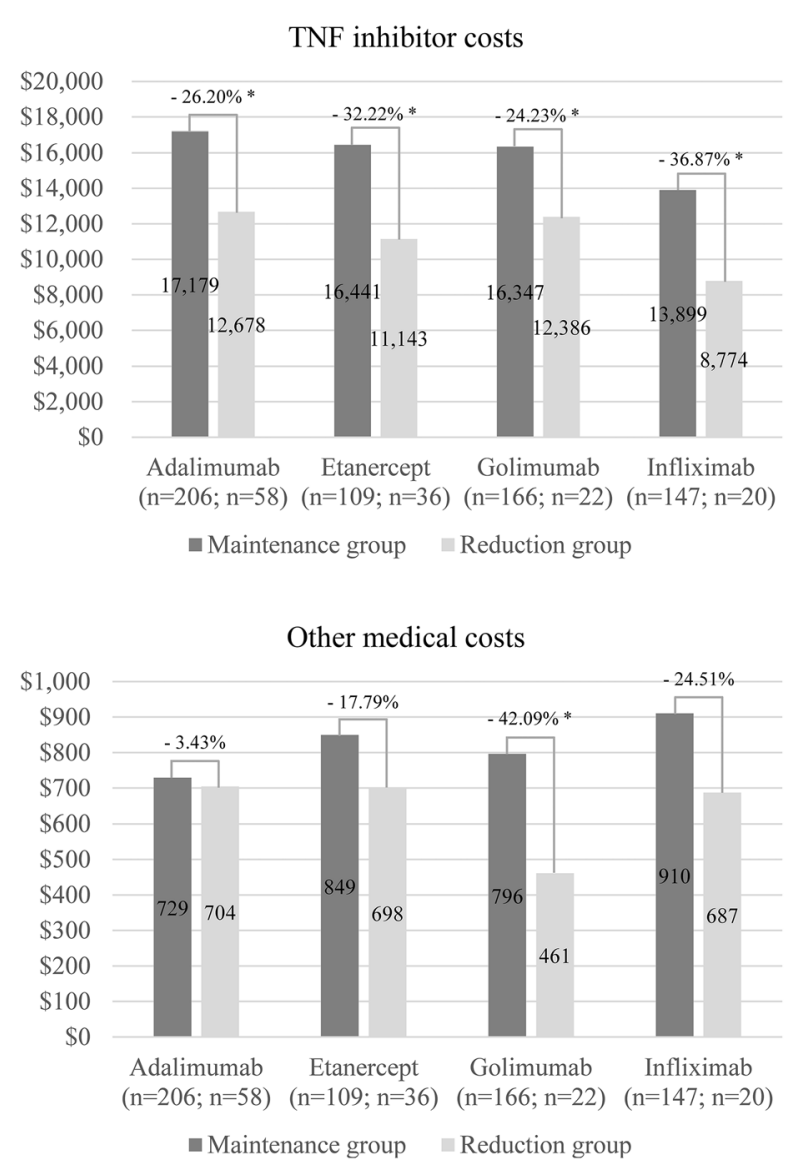

Fig. 3 Graphs of adjusted follow-up healthcare costs. The graphs described AS-related healthcare costs in patients who were continuously treated with TNFi during the follow-up period. Generalized linear model (GLM) with

weekly doses. Moreover, we strictly defined dose reduction as a decrease in the dose by more than $50 \%$. Because there may be some dose reduction or interval control for various reasons in patients, this definition may be more reasonable for assessing the rate of dose reduction in a retrospective study. Interestingly, despite the different doses and intervals for each TNFi, the percentage of reduced doses in patients with dose reduction was not different among TNFis in both main and sensitivity analyses $(p=0.8673$ and 0.1193 , respectively).

A few clinical studies have reviewed the dose reduction of biologics in patients with AS. In a randomized controlled study, remission was maintained in $86.3 \%$ of patients who received $50 \mathrm{mg}$ etanercept every alternate week and in
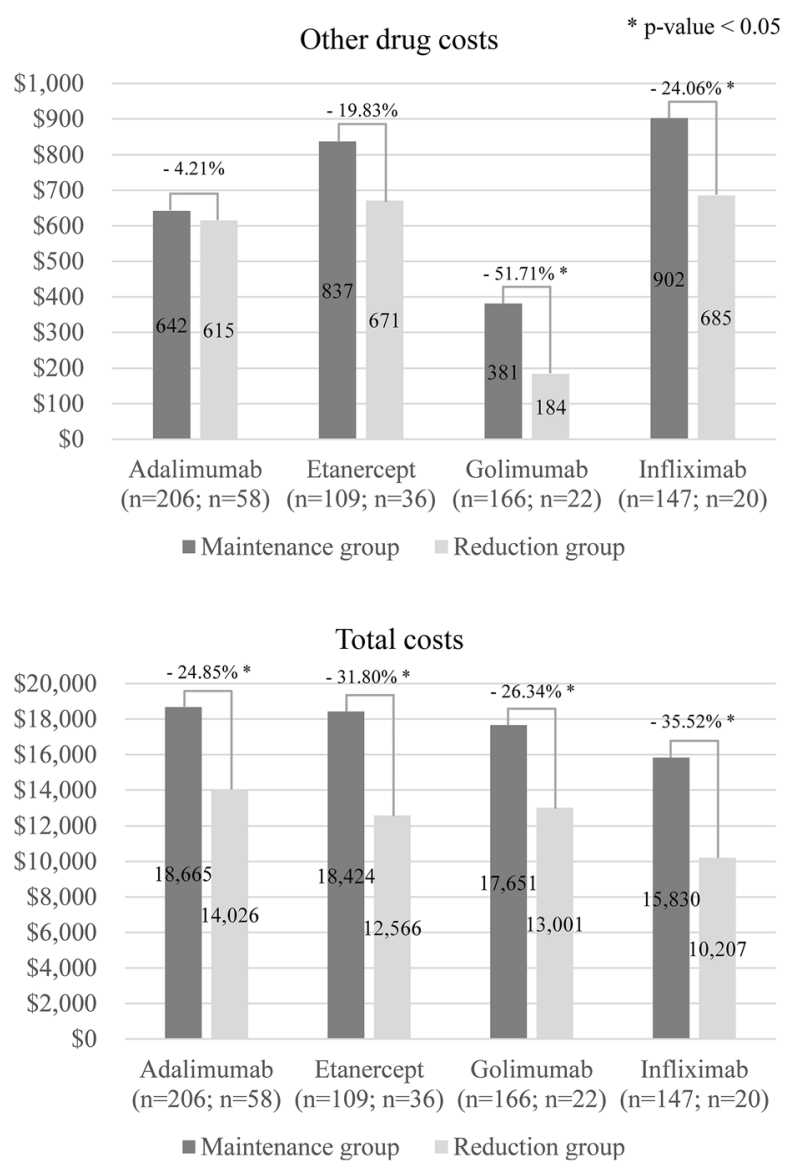

gamma distribution and log link function was used to calculate the adjusted healthcare costs and evaluate the cost difference between the dose reduction and the dose maintenance group (Unit: \$)

$90.4 \%$ of patients who received $50 \mathrm{mg}$ etanercept every week [25]. However, a pilot randomized controlled trial on tapering etanercept from 50 to $25 \mathrm{mg}$ weekly in patients with AS showed that only $52 \%$ of patients maintained a treatment response [26]. Therefore, dose tapering was not recommended as a standard approach for treatment in the 2019 update of the American College of Rheumatology [12, 27].

Zavada et al. reported that reduced doses of TNFi in patients with AS showed similar clinical outcomes and reduced medical expenses [24]. They used a multivariate matching method for a small number of patients over 1 year and estimated the annual costs of TNFi and costs of TNFi per quality-adjusted life years. The mean difference in costs associated with TNFi use was 
$-€ 4,214$ ( $-€ 4707$ to $-€ 3701)$ per year with the reduced dosing strategy. Although our study differed from their definition of tapering, we showed a cost reduction of approximately $\$ 5,000$, with significant overall medical cost changes in the dose reduction group. Consequently, TNFi dose reduction was found to increase medical cost savings from 24.85 to $35.52 \%$ in patients with AS. In addition, other AS-related healthcare costs (excluding TNFi costs) did not increase following TNFi dose reduction. This suggests that reduced TNFi dose might be maintained without additional medical expenses that may be incurred due to worsening disease activity.

Among the TNFis, infliximab was associated with the lowest TNFi cost and total cost at standard and reduced doses. Notably, golimumab significantly reduced other drug costs and other medical costs in the dose reduction group. Because the dosing interval of golimumab was 4 weeks longer than that of adalimumab or etanercept, hospital visits might have been shorter than that with adalimumab or etanercept use, leading to reduced medical costs. In patients with AS, healthcare expenses may be affected by the method and interval of TNFi administration.

There was a difference in concomitant drug use among the different TNFi-administered patients; a high rate of corticosteroid use was observed, especially in those treated with infliximab. This may be owing to the censoring of both uveitis and peripheral arthritis treatments, such as eye drop and intra-articular injection of corticosteroids with intermittent administration. Moreover, infliximab is frequently administered with corticosteroids to prevent adverse effects such as an allergic reaction with infusions. The percentage of sulfasalazine use was different among the TNFi groups $(p=0.0105)$. This may be related to the long dosing interval of infliximab; however, further research is needed in this regard.

This study had some limitations. Firstly, although the national insurance claims database provides extensive information for research purposes, it does not provide certain crucial information, such as laboratory findings, subjective symptoms related to disease activity, and patient-reported outcomes. However, according to the reimbursement criteria required to maintain TNFi, the Bath Ankylosing Spondylitis Disease Activity Index (BASDAI) should be measured every 6 months, and if the BASDAI is $<4$, TNFi expense can be reimbursed for 6 months. Thus, patients who maintain TNFi treatment can be considered to have a low disease activity. Secondly, it was difficult to identify the various reasons for dose reduction due to limitations in the insurance claims data. Thirdly, the period of study was only 2 years because of the limited period of HIRA data available for the study.

\section{CONCLUSIONS}

We identified treatment patterns among patients with AS administered various TNFis using Korean health insurance data. Among patients who maintained TNFi treatment, $17.80 \%$ were prescribed TNFis with a dose reduction of more than $50 \%$ within 2 years. The pattern of dose reduction was different for each TNFi. The cost of AS-related total medical care significantly increased medical cost savings from 24.85 to $35.52 \%$ following TNFi dose reduction. If patients with potential for dose reduction are screened well, healthcare costs may be reduced without worsening disease activity.

\section{ACKNOWLEDGEMENTS}

Funding. This work and the journal's Rapid Service Fee were supported by Pfizer Inc.

Authorship. All named authors meet the International Committee of Medical Journal Editors (ICMJE) criteria for authorship for this article, take responsibility for the integrity of the work as a whole, and have given their approval for this version to be published.

Authorship Contributions. BSK, YCL, MYL, JYJ, HJY, and THK contributed to study conception and design. YCL, MYL, ISO, and JYS 
performed data acquisition and analysis. BSK, YCL, and THK wrote the manuscript. BSK, YCL, MYL, and THK were involved in data interpretation. All authors took part in revising the manuscript critically for important intellectual content, gave final approval of the manuscript to be published, and agreed to be accountable for all aspects of the work.

Prior Presentation. This study was presented at the 2019 American College of Rheumatology annual scientific meeting in Atlanta, Georgia, USA

Disclosures. Ja-Young Jeon and Hyun-Jeong Yoo are employees of Pfizer Inc. Bon San Koo, Yu-Cheol Lim, Min-Young Lee, In-Sun Oh, JuYoung Shin and Tae-Hwan Kim have nothing to disclose.

Compliance with Ethics Guidelines. This study was performed in accordance with the Helsinki Declaration of 1964 and its later amendments. The study protocol was approved by the institutional review boards of the Inje University Seoul Paik Hospital (2018-07-011), Sungkyunkwan University (SKKU 2018-02-006), and Hanyang University (2017-11-020). Informed consent was waived by the institutional review boards because this was a retrospective study that used data from insurance claims.

Data Availability. The data can be obtained from the insurance claims database of the Health Insurance Review \& Assessment Service (HIRA) in South Korea (http://www.hira.or.kr/ eng/main.do). Data were provided with a customized research database set for ankylosing spondylitis, and we obtained permission to access and use the data from the HIRA. No additional data are available.

Open Access. This article is licensed under a Creative Commons Attribution-NonCommercial 4.0 International License, which permits any non-commercial use, sharing, adaptation, distribution and reproduction in any medium or format, as long as you give appropriate credit to the original author(s) and the source, provide a link to the Creative Commons licence, and indicate if changes were made. The images or other third party material in this article are included in the article's Creative Commons licence, unless indicated otherwise in a credit line to the material. If material is not included in the article's Creative Commons licence and your intended use is not permitted by statutory regulation or exceeds the permitted use, you will need to obtain permission directly from the copyright holder. To view a copy of this licence, visit http:// creativecommons.org/licenses/by-nc/4.0/.

\section{REFERENCES}

1. O'Shea JJ, Gadina M. Selective Janus kinase inhibitors come of age. Nat Rev Rheumatol. 2019;15(2): $74-5$.

2. Schmid AS, Neri D. Advances in antibody engineering for rheumatic diseases. Nat Rev Rheumatol. 2019;15(4):197-207.

3. Davis JC, van der Heijde DM, Braun J, et al. Sustained durability and tolerability of etanercept in ankylosing spondylitis for 96 weeks. Ann Rheum Dis. 2005;64(11):1557-62.

4. Inman RD, Davis JC Jr, Heijde D, et al. Efficacy and safety of golimumab in patients with ankylosing spondylitis: results of a randomized, double-blind, placebo-controlled, phase III trial. Arthritis Rheum. 2008;58(11):3402-12.

5. van der Heijde D, Dijkmans B, Geusens $P$, et al. Efficacy and safety of infliximab in patients with ankylosing spondylitis: results of a randomized, placebo-controlled trial (ASSERT). Arthritis Rheum. 2005;52(2):582-91.

6. van der Heijde D, Kivitz A, Schiff $\mathrm{MH}$, et al. Efficacy and safety of adalimumab in patients with ankylosing spondylitis: results of a multicenter, randomized, double-blind, placebo-controlled trial. Arthritis Rheum. 2006;54(7):2136-46.

7. Park EJ, Kim H, Jung SM, Sung YK, Baek HJ, Lee J. The use of biological disease-modifying antirheumatic drugs for inflammatory arthritis in Korea: results of a Korean expert consensus. J Rheum Dis. 2020;27(1):4-21.

8. Edwards CJ, Fautrel B, Schulze-Koops H, Huizinga TWJ, Kruger K. Dosing down with biologic 
therapies: a systematic review and clinicians' perspective. Rheumatology (Oxford). 2017;56(11): 1847-56.

9. Navarro-Compan V, Plasencia-Rodriguez C, de Miguel E, et al. Anti-TNF discontinuation and tapering strategies in patients with axial spondyloarthritis: a systematic literature review. Rheumatology (Oxford). 2016;55(7):1188-94.

10. Haibel H, Heldmann F, Braun J, Listing J, Kupper H, Sieper J. Long-term efficacy of adalimumab after drug withdrawal and retreatment in patients with active non-radiographically evident axial spondyloarthritis who experience a flare. Arthritis Rheum. 2013;65(8):2211-3.

11. Song $\mathrm{IH}$, Althoff $\mathrm{CE}$, Haibel $\mathrm{H}$, et al. Frequency and duration of drug-free remission after 1 year of treatment with etanercept versus sulfasalazine in early axial spondyloarthritis: 2-year data of the ESTHER trial. Ann Rheum Dis. 2012;71(7):1212-5.

12. Ward MM, Deodhar A, Gensler LS, et al. 2019 Update of the American College of Rheumatology/ Spondylitis Association of America/Spondyloarthritis Research and Treatment Network Recommendations for the Treatment of Ankylosing Spondylitis and Nonradiographic Axial Spondyloarthritis. Arthritis Care Res (Hoboken). 2019;71(10):1285-99.

13. Kim JA, Yoon S, Kim LY, Kim DS. Towards Actualizing the Value Potential of Korea Health Insurance Review and Assessment (HIRA) Data As A Resource For Health Research: Strengths, Limitations, Applications, And Strategies For Optimal Use Of HIRA data. J Korean Med Sci. 2017;32(5):718-28.

14. Kim L, Kim JA, Kim S. A guide for the utilization of Health Insurance Review and Assessment Service National Patient Samples. Epidemiol Health. 2014;36:e2014008.

15. Kwon S. Payment system reform for health care providers in Korea. Health Policy Plan. 2003;18(1): 84-92.

16. Seong JM, Choi NK, Shin JY, et al. Differential cardiovascular outcomes after dipeptidyl peptidase- 4 inhibitor, sulfonylurea, and pioglitazone therapy, all in combination with metformin, for type 2 diabetes: a population-based cohort study. PLoS ONE. 2015;10(5):e0124287.

17. Bae SO, Kang GW. A comparative study of the disease codes between Korean National Health Insurance claims and Korean national hospital discharge in-depth injury survey. Health Policy Manag. 2014;24(4):322-9.
18. Park JS, Jang HD, Hong JY, et al. Impact of ankylosing spondylitis on depression: a nationwide cohort study. Sci Rep. 2019;9(1):6736.

19. Joyce AT, Gandra SR, Fox KM, Smith TW, Pill MW. National and regional dose escalation and cost of tumor necrosis factor blocker therapy in biologicnaive rheumatoid arthritis patients in US health plans. J Med Econ. 2014;17(1):1-10.

20. Gratacos J, Pontes C, Juanola X, et al. Non-inferiority of dose reduction versus standard dosing of TNF-inhibitors in axial spondyloarthritis. Arthritis Res Ther. 2019;21(1):11.

21. Walsh JA, Adejoro O, Chastek B, Palmer JB, Hur P. Treatment patterns among patients with psoriatic arthritis treated with a biologic in the united states: descriptive analyses from an administrative claims database. J Manag Care Spec Pharm. 2018. https:// doi.org/10.18553/jmcp.2018.17388.

22. Halpern R, Nadkarni A, Kalsekar I, et al. Medical costs and hospitalizations among patients with depression treated with adjunctive atypical antipsychotic therapy: an analysis of health insurance claims data. Ann Pharmacother. 2013;47(7-8): 933-45.

23. Park JW, Kim HA, Shin K, et al. Effects of tapering tumor necrosis factor inhibitor on the achievement of inactive disease in patients with axial spondyloarthritis: a nationwide cohort study. Arthritis Res Ther. 2019;21(1):163.

24. Zavada J, Uher M, Sisol K, et al. A tailored approach to reduce dose of anti-TNF drugs may be equally effective, but substantially less costly than standard dosing in patients with ankylosing spondylitis over 1 year: a propensity score-matched cohort study. Ann Rheum Dis. 2016;75(1):96-102.

25. Cantini F, Niccoli L, Cassara E, Kaloudi O, Nannini C. Duration of remission after halving of the etanercept dose in patients with ankylosing spondylitis: a randomized, prospective, long-term, follow-up study. Biologics. 2013;7:1-6.

26. Yates M, Hamilton LE, Elender F, et al. Is etanercept $25 \mathrm{mg}$ once weekly as effective as $50 \mathrm{mg}$ at maintaining response in patients with ankylosing spondylitis? A Randomized Control Trial. J Rheumatol. 2015;42(7):1177-85.

27. Ward MM, Deodhar A, Gensler LS, et al. 2019 Update of the American College of Rheumatology/ Spondylitis Association of America/Spondyloarthritis Research and Treatment Network Recommendations for the Treatment of Ankylosing Spondylitis and Nonradiographic Axial Spondyloarthritis. Arthritis Rheumatol. 2019;71(10): 1599-613. 